\title{
Effects of human anthropometry and personal protective equipment on space requirements
}

\author{
John W. Kozey ${ }^{\mathrm{a}, *}$, Chris J. Brooks ${ }^{\mathrm{b}}$, Sherma L. Dewey ${ }^{\mathrm{a}}$, Robert C. Brown ${ }^{\mathrm{c}}$, \\ Kimberly A. Howard ${ }^{\mathrm{b}}$, Danika Drover ${ }^{\mathrm{d}}$, Scott MacKinnon ${ }^{\mathrm{d}}$ and John McCabe ${ }^{\mathrm{a}}$ \\ ${ }^{a}$ Dalhousie University, Halifax, Nova Scotia, Canada \\ ${ }^{\mathrm{b}}$ Survival Systems Limited, Dartmouth, Nova Scotia, Canada \\ ${ }^{\mathrm{c}}$ Marine Institute, St. John's, Newfoundland, Canada \\ ${ }^{\mathrm{d}}$ Memorial University, St. John's, Newfoundland, Canada
}

\begin{abstract}
Representative samples of offshore workers engaged in the use of totally enclosed lifeboats were recruited in two different regions of Atlantic Canada for this study. Body mass, height and three selected anthropometric dimensions were measured with and without the presence of an immersion suit. Statistical comparisons were made between the two groups and to the main criteria values for body weight and space allocation used international standards for lifeboat capacity rating. There was no difference in the height, body mass and BMI values between the two groups. Both groups were found to be considerably heavier than the IMO Life Saving Code standard of $75 \mathrm{~kg}$. Not surprisingly, the shoulder breadths measurements were always greater than the hip breadth measurements. The seat pan allocation of $430 \mathrm{~mm}$ was found to be inadequate for this population and needs to be increased. Finally, the wearing of an immersion suit increases the physical size of each subject by substantial amounts. The magnitude of increase is related to the type of suit and whether there was external compression applied during the measurement. It was recommended that the international standard should be altered by reducing the lifeboat capacity ratings by $20 \%$.
\end{abstract}

Keywords: Human anthropometry, lifeboats, immersion suits, standards

\section{Introduction}

It has long been accepted that the ideal performance of the human will occur when there is an optimal match among the human-machine-environment. In the case of personal protective equipment design this means designing the clothing/equipment to provide the optimal fit to the user while minimizing any changes in physical capabilities. From an overall systems approach it is important to ensure that the capability of the user plus equipment to any other machines he or she may interact with or operate has not been compromised. An immersion suit is a well established example of personal protective equipment (PPE) which is worn to provide thermal protection from the effects of being immersed in cold water. While the primary application is protection, the suit must allow the wearer to perform any occupational tasks directly related to survival. Further the protected individual must be accommodated in any emergency means (vehicle, aircraft or vessel) of transport.

\footnotetext{
*Address for correspondence: John Kozey, School of Health and Human Performance, Dalhousie University, Halifax, NS, Canada, B3H 3J5. Tel.: +1 902494 1148; Fax: +1 902494 5120; E-mail: John.Kozey@ dal.ca.
} 


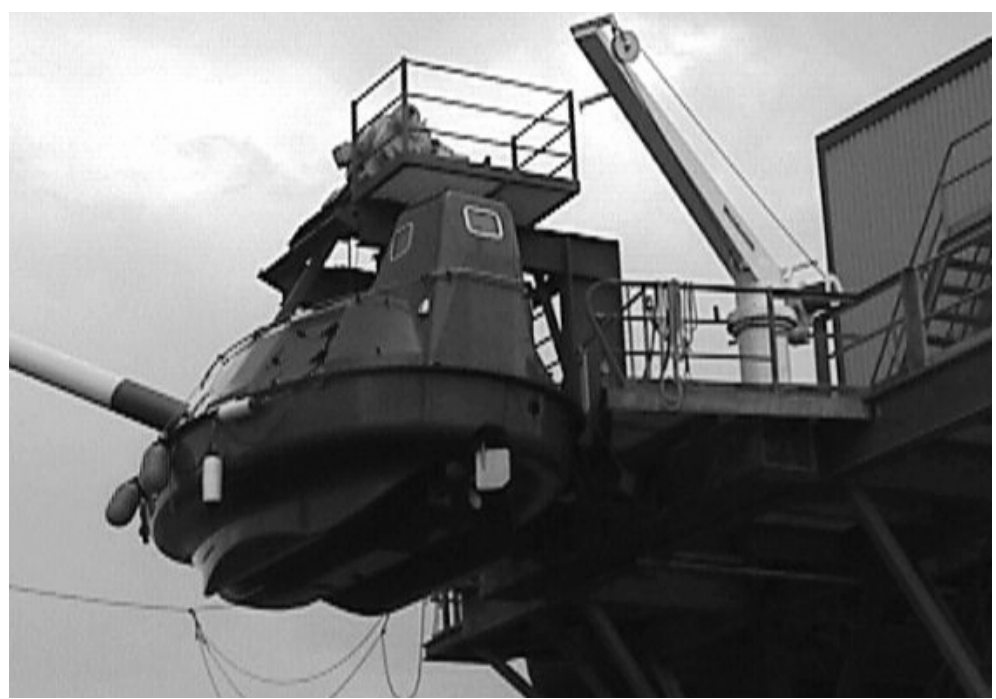

Fig. 1. Typical offshore and marine abandonment lifeboat.

Human anthropometry is important in obtaining the proper fit and consequently the performance of personal protective equipment. The critical human dimensions necessary for proper fit can vary for one or two dimensions to multiple dimensions depending on the application. Whenever possible universal sizing is limited to two critical dimensions to minimize the number of different size combinations necessary in the final product [6,8]. Laing et al. [6] proposed a new method of grouping dimensions and applied the method to sizing of New Zealand firefighters. Kozey et al. [4] have presented data on offshore workers for the purposes of using the information to better design immersion suits and workspaces critical for emergency egress conditions. In addition to general measures of height and body mass, specific dimensions of limb lengths and circumferences were found to be critical for obtaining proper sizing and seals to prevent water leakage into the suit. Even after proper fitting of the human-suit system the affects the human-suit system must now be integrated into the machine/workspace design.

There is already evidence that shows that the wearing of personal protective equipment increases anthropometric dimensions and reduces functional reach $[2,4,6,7]$. Recent work related to the maritime environment on offshore workers by Reilly et al. [9] has shown that wearing of a helicopter passenger suit increased the structural dimensions by 13 to $150 \mathrm{~mm}$ depending on the particular dimension. They also reported that when a subject was seated and wearing a helicopter passenger suit, that functional reach above shoulder height was restricted. Uppu et al. [10] have shown similar effects of pressurized suits on functional reach of Asian aircrew.

Once a person has donned an immersion suit his or her mobility, reach and physical space requirements are altered. The focus of this study is the impact of the wearing of an immersion suit on the space requirements in a lifeboat typical of the one shown in Fig. 1. The origins of this study arose during the $47^{t h}$ session of the Design and Equipment sub-committee of the International Marine Organization (IMO) in 2004. At the time the IMO was in the process of making immersion suits mandatory on all ocean going vessels and a concern was raised of the impact that wearing an immersion suit will have on the human capacity rating of lifeboats. The current lifeboat standard (Safety of Life at Sea, SOLAS III/32) considers the average mariner to have a body mass of $74 \mathrm{~kg}$ and allocates a linear buttock space of $430 \mathrm{~mm}$. 


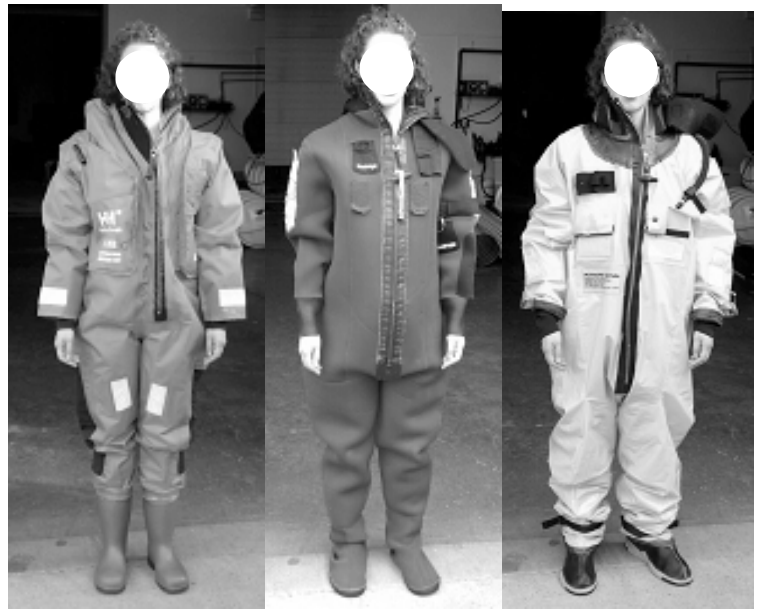

A

B

$\mathrm{C}$

Fig. 2. Immersion suits used in the study.

\subsection{Objectives of this study}

The primary objective of this study was to measure the change in structural dimensions of subjects due to wearing an immersion suit. A secondary objective was to determine if there were differences in anthropometric dimensions of offshore workers within different regions of Atlantic Canada and the third objective was to relate these changes in dimensions due to the immersion suit to the IMO standard for lifeboat capacity ratings. The following research questions were examined:

1. Determine if there are differences in selected body dimensions of subjects in two different regions in Atlantic Canada (Nova Scotia and Newfoundland).

2. Measurement of selected anthropometric dimensions of a typical sample of subjects dressed in work clothing.

3. The effect of wearing three different immersion suits on shoulder and hip breadth in seated and standing postures.

4. The effect of wearing three typical immersion suits on the maximum loading capacity of a lifeboat as reported in IMO standard (SOLAS III/32).

Separate data collections were conducted simultaneously with one research group based in Dartmouth, Nova Scotia at Survival Systems Limited and the second group in St John's, Newfoundland at Memorial University of Newfoundland and the Marine Institute. Ethics approval was obtained through the Dalhousie University, Health Sciences Research Ethics Board, Nova Scotia and the Memorial University of Newfoundland Ethics Committee, St. John's, Newfoundland, respectively. The two centres are located 850 kilometers apart and both geographic areas have active offshore developments in oil and gas.

\section{Methods}

Prior to all testing the two research groups met and standardized the data collection protocols and methods to ensure consistency of the measurement protocols and methods. However, subjects in the St 

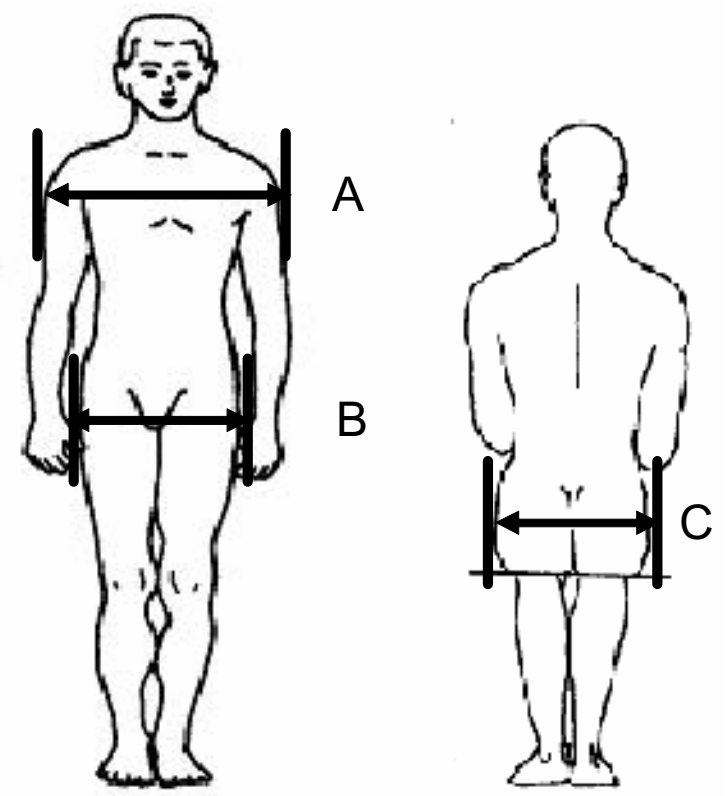

Fig. 3. Schematic of the three anthropometric dimensions. The original images are from Van Cott and Kinkade (1972).

John's group were only available for a limited period of time and not all of the testing was able to be completed on each subject. The same type of measurement devices were used in the separate locations. All subjects provided informed consent prior to participation in the study.

Hip and shoulder breadths measurements were recorded for four different conditions in Dartmouth: normal work clothing and three different immersion suits typically used in offshore Nova Scotia (Fig. 2A, $\mathrm{B}$ and C). Hip and shoulder measurements were performed for two conditions in St. John's: normal work clothing and one immersion suit (Suit $\mathrm{D}$ ), which is similar to Suit $1 \mathrm{C}$ and made by the same manufacturer.

\subsection{Structural anthropometry (Dartmouth and St. John's)}

Overall, height and body mass measures were recorded using a standing anthropometer and weigh scale, respectively. Each seafarer's body mass index (BMI, $\mathrm{Kg} / \mathrm{m}^{2}$ ) was calculated using the height and mass data. Standard structural anthropometric techniques were used to record the hip and shoulder breadth measures. Both subject pools consisted of males and females the ratio of which was representative of the population as a whole. All the subjects in both areas were recruited from the pool of subjects who attend the required marine survival training courses in each of the respective areas. Shown in Fig. 3 is an image of a standing and a seated person and the three breadth dimensions taken using the anthropometer. The three dimensions were: A - Standing shoulder breadth, B - Standing hip breadth, and C - Seated hip breadth.

Bi-deltoid (shoulder breadth) and bi-trochanteric (hip breadth) measurements were taken on each subject while wearing his or her standard work clothes and while wearing each of the three different immersion suits worn over the top of their work clothes (the condition that would occur in marine abandonment). Standard anatomical landmarks were used during the measurement process to define the locations of the measures [3,11]. However, it was not feasible to palpate the landmarks for the uncompressed suit measures and even with compression palpation over the suit is problematic. To 

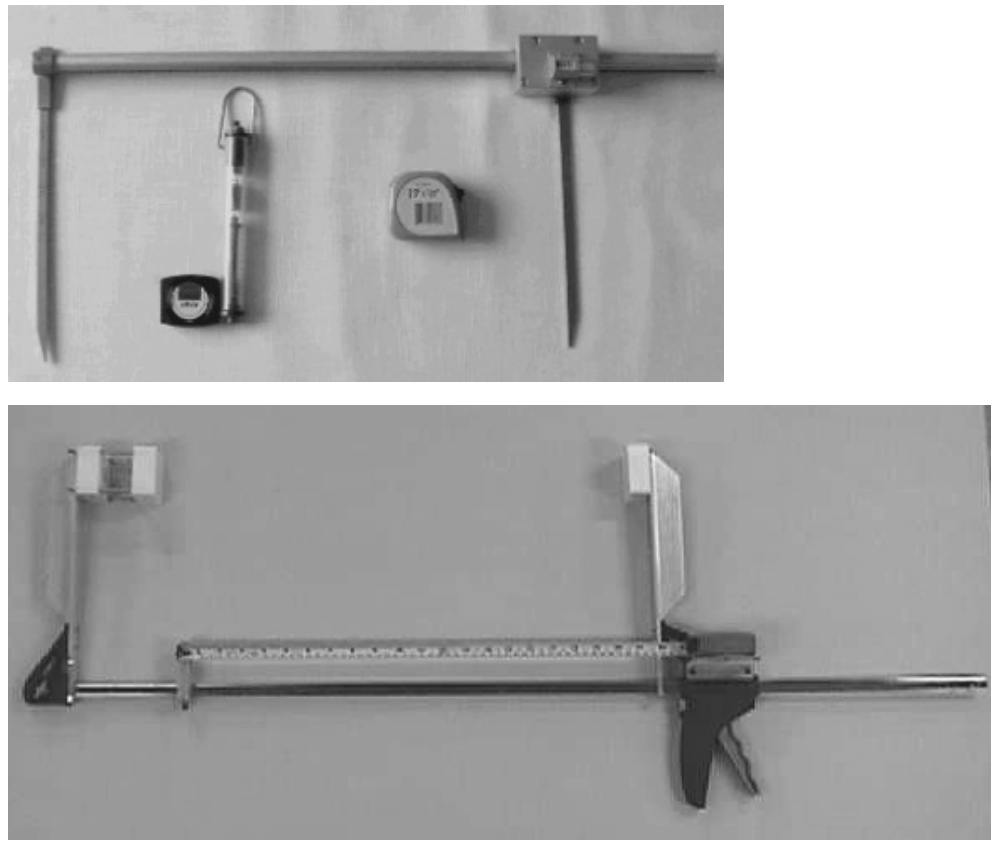

Fig. 4. Standard Harpenden anthropometer (above) and new device (below) built for this study.

control for this problem a method described by Reilly et al. [9] was used. The vertical height of each landmark was recorded during the work clothes measures. Then during the suited conditions the vertical positioning of the anthropometer was positioned using the vertical measures after adjustment for the boot height.

Shown in Fig. 4 is a traditional Harpenden anthropometer used in past anthropometric studies and a new anthropometer developed specifically for this study. Preliminary data indicated that the shoulder breadths to be recorded would exceed the measurement range of the original device; therefore an enlarged version of the anthropometer was built to accommodate the wider measures. A second modification was the addition of a force gauge to record the amount of compression the experimenter produced on the subject during the measurements. This force gauge was important in standardizing the measurements, providing practical repeatable measurements to identify a comfortable fit in the seat and to consistently reproduce a very tight fit in the seat. During the suited conditions each measure was first recorded using no compression followed by standardized compression of $2.7 \mathrm{kgs}(6 \mathrm{lbs})$ to represent a very tight fit in the lifeboat.

\subsection{Modeling of lifeboat capacities}

Additional calculations and observations were made on the practical application of the anthropometric data to the fit of the humans in the lifeboat. This was accomplished by comparing the shoulder and hip breadth measures of a random subset of the subjects to the linear space allocation of 430 millimeters in the IMO Life Saving Appliance Code. A simple mathematical model was developed to calculate the cumulative length of the row of subjects compared to the value used in the standard. The subject's were modeled as being seated side-by-side just touching each other. The cumulative length was the addition of the breadth measure of each person as one moved along the row. A series of 5 representative sub-samples were randomly formed from the total sample for the model. 
Table 1

Descriptive statistics for seafarers in Atlantic Canada

\begin{tabular}{lccccc}
\hline Measure & \multicolumn{2}{c}{ Nova Scotia $(n=87)$} & & \multicolumn{2}{c}{ Newfoundland $(n=84)$} \\
\cline { 2 - 3 } \cline { 5 - 6 } & Mean & SD & & Mean & SD \\
\hline Age $(\mathrm{yr})$ & 37.1 & 9.8 & & 37.7 & 9.6 \\
Experience $(\mathrm{yr})$ & 6.4 & 8.1 & & 5.4 & 6.1 \\
Mass $(\mathrm{Kg})$ & 86.3 & 15.5 & & 88.4 & 17.4 \\
Height $(\mathrm{mm})$ & 1748 & 71.7 & & 1751 & 81.5 \\
BMI $\left(\mathrm{Kg} / \mathrm{m}^{2}\right)$ & 28.2 & 4.4 & & 28.6 & 4.5 \\
\hline
\end{tabular}

Table 2

Structural dimensions $(\mathrm{mm})$ for the two study groups and all conditions

\begin{tabular}{|c|c|c|c|c|c|c|c|c|c|c|c|c|c|}
\hline \multirow[t]{3}{*}{ Dimension } & & \multicolumn{8}{|c|}{ Nova Scotia } & \multicolumn{4}{|c|}{ Newfoundland } \\
\hline & & \multicolumn{2}{|c|}{ No suit } & \multicolumn{2}{|c|}{ Suit A } & \multicolumn{2}{|c|}{ Suit B } & \multicolumn{2}{|c|}{ Suit C } & \multicolumn{2}{|c|}{ No suit } & \multicolumn{2}{|c|}{ Suit D } \\
\hline & & Mean & SD & Mean & SD & Mean & SD & Mean & SD & Mean & SD & Mean & SD \\
\hline Shoulder & Normal & 515 & 38 & 592 & 38 & 604 & 38 & 595 & 31 & 514 & 46 & 553 & 49 \\
\hline breadth & Comp & 441 & 35 & 458 & 33 & 472 & 36 & 468 & 39 & * & $*$ & 484 & 40 \\
\hline Hip breadth & Normal & 383 & 26 & 424 & 27 & 427 & 31 & 425 & 29 & 368 & 31 & 385 & 30 \\
\hline standing & Comp & 322 & 23 & 327 & 23 & 330 & 23 & 335 & 26 & $*$ & $*$ & 338 & 26 \\
\hline Hip breadth & Normal & 419 & 29 & 464 & 25 & 452 & 23 & 459 & 29 & 386 & 31 & 425 & 35 \\
\hline seated & Comp & 357 & 28 & 376 & 30 & 377 & 29 & 380 & 29 & $*$ & $*$ & 362 & 30 \\
\hline
\end{tabular}

*Not measured.

\subsection{Data analysis}

\subsubsection{Structural anthropometry}

The anthropometric data were collated and standard descriptive statistics (mean, standard deviation, $5^{\text {th }}, 50^{\text {th }}$ and $95^{\text {th }}$ percentile values) were calculated using MINITAB. Pearson Product Moment Correlations (PPMC) were calculated on the mass, height, and other non-compressed structural dimensions. To test for the effects of suits and compression on the breadth measures an ANOVA (2 (conditions) by 4 (clothing conditions)) was used to test for any significant main and interaction effects. Because the data collected in Newfoundland did not contain the compressed, work clothes condition, the ANOVA analysis was completed on the Nova Scotia data alone.

\section{Results}

\subsection{Study subjects - demographics}

The general demographic information (mean and standard deviation) for the two sample groups are shown in Table 2. There were 80 males and 7 females in the Nova Scotia sample which provided a male/female ratio of approximately 11:1 typical for offshore marine workers. The subjects ranged in age from 18 to 58 years. The mass values ranged from 46.8 to $145.5 \mathrm{~kg}$, height ranged from 1563 to 1913 mm, Body Mass Index (BMI) ranged from 17.9 to 45.7, and marine work experience ranged from 0 to 34 years. Similar height, mass and BMI values were obtained for the 84 subjects ( 74 males and 10 females) tested in Newfoundland as shown in Table 1.

A series of t-tests were conducted to compare the demographic measurements between the two groups. There was no significant difference in the age, experience, mass, height and BMI between the two groups. However, there were significant differences in the two hip breadth measures between the two groups. In 
both cases the data from Newfoundland were less than the hip breadths measurements of the samples in Nova Scotia by 15 and $33 \mathrm{~mm}$ for the standing and seated measures, respectively.

\subsection{Structural measurements}

Presented in Table 2 are the mean and standard deviation of the physical dimensions for shoulder breadth, hip breadth (standing) and hip breadth (seated) in work clothes (control), and wearing the immersion suits in the comfortable fit and the compressed fit condition for the two study groups. It was not possible to measure the compressed, work clothes condition for the subjects in the Newfoundland portion of the study due to the time constraints of the subjects during the testing.

\subsubsection{Shoulder breadth}

The structural measurements for the two group are shown in Table 2. The mean shoulder breadths for Nova Scotia group for the uncompressed measures were 515, 592, 604 and $595 \mathrm{~mm}$ for the work clothes and three suited conditions, respectively. The shoulder breadth measures increased from the work clothes conditions by means of $77 \mathrm{~mm}$ for Suit A, $89 \mathrm{~mm}$ Suit B and $80 \mathrm{~mm}$ for Suit C in the uncompressed state.

For the compressed state the mean shoulder breadths were 441, 458, 472 and $468 \mathrm{~mm}$ for the work clothes and 3 suited conditions, respectively. The mean increase in shoulder breadth was $17 \mathrm{~mm}$ for Suit A, $31 \mathrm{~mm}$ for Suit B, and $27 \mathrm{~mm}$ for Suit C compared to the work clothes condition.

The mean shoulder breadths of the Newfoundland sample were 515 and $553 \mathrm{~mm}$ for the work clothes and immersion suit condition for a difference of $39 \mathrm{~mm}$. There was no difference in the mean shoulder breadth values between the two regional samples (515 and $514 \mathrm{~mm}$ ).

Comparing the effects of compression on the shoulder breadths, it was found that the compression decreased the work clothes breadth, a mean of $74 \mathrm{~mm}$. Compression of the suits decreased the shoulder breadth measures by 134, 132, 127 and $69 \mathrm{~mm}$ for Suits A, B, C and D, respectively.

\subsubsection{Hip breadth (standing)}

For the Nova Scotia data the uncompressed, standing hip breadth values were 383, 424, 425 and 427 $\mathrm{mm}$ for the work clothes and three suited conditions, respectively. The hip breadth measurements had a significant increase of $41 \mathrm{~mm}$ for Suit A, $42 \mathrm{~mm}$ for Suit B and $44 \mathrm{~mm}$ for Suit C in the uncompressed state.

Compression significantly reduced the standing hip breadth measures to $322,327,335$ and $330 \mathrm{~mm}$ for the work clothes, and each of the three suits, respectively. Comparing the work clothes to the suits for the compressed state, the mean increase was $4 \mathrm{~mm}$ for Suit A, $9 \mathrm{~mm}$ for Suit B, and $14 \mathrm{~mm}$ for Suit C. The only mean difference for the compressed condition that was significant was Suit C compared to the work clothes. $(t=3.24, p<0.03)$.

Consistent with the results for the shoulder breadth measures, the ANOVA for standing hip breadth had significant main effects of suit $(\mathrm{F}=112.1, \mathrm{df}=3,602, p<0.01)$ and conditions $(\mathrm{F}=5015, \mathrm{df}=1$, $602, p<0.01)$. Simply stated the suited measures were greater than the work clothes measures. There was also a significant interaction of the suit by condition effects $(\mathrm{F}=49.4, \mathrm{df}=3,602, p<0.01)$, this is the effect of compression on the different suit types. Again Suits A and B had a greater change in size due to the compression than Suit $C$. 


\subsubsection{Hip breadth (seated)}

The standing hip breadth values were 419, 464, 459 and $452 \mathrm{~mm}$ for the work clothes and three suited conditions, respectively. The hip breadth measurements increased significantly by a mean of $45 \mathrm{~mm}$ for Suit A, $34 \mathrm{~mm}$ for Suit B and $41 \mathrm{~mm}$ for Suit C in the uncompressed states. For the compressed state, the mean increase was $19 \mathrm{~mm}$ for Suit A, $20 \mathrm{~mm}$ for Suit B and $23 \mathrm{~mm}$ for Suit C.

Consistent with the results for the hip breadth standing, the ANOVA results for the seated hip breadth had significant main effects of suit $(\mathrm{F}=287.5, \mathrm{df}=3,603, p<0.01)$ and conditions $(\mathrm{F}=7114, \mathrm{df}=$ $1,602, p<0.01)$. Again, the suited measures were greater than the work clothes measures. There was a significant interaction of suit by condition effects $(\mathrm{F}=36.9, \mathrm{df}=1,602, p<0.01)$. Suit $\mathrm{B}$ had the greatest change in size due to the compression.

\subsubsection{Summary of main outcome measures}

The statistical analysis for this study examined two main effects, which were: (1) the wearing of work clothes versus immersion suits and (2) the effects of no compression versus compression on the shoulder and hip breadth measures. In addition, further comparisons were made of the combination of the effects of suits and compression (interaction effects) on these measures. Overall there were significant main effects of suits and condition (compression and no compression) and a significant interaction of suits by conditions. The shoulder breadth, hip breadth standing and hip breadth seated dimensions recorded in the work clothes were significantly smaller than the same dimensions for any of the uncompressed, suited conditions $(\mathrm{F}=361.5 \mathrm{df}=3,603, p<0.01)$. With compression all three anthropometric measurements were significantly less than the uncompressed measures $(\mathrm{F}=6633.5, \mathrm{df}=1,603, p<0.01)$. An equally important finding was the significant suit by compression interaction effect that highlights two important points. Compression had a significantly greater change in the suited measures than the work clothes measures and compression had significantly less of an effect on immersion Suit $\mathrm{C}$ than the other two suits. $(\mathrm{F}=99.6, \mathrm{df}=3,603, p<0.01)$. An example of this result for the shoulder breadth measure is shown graphically in Fig. 5. The interaction effect as shown in this pattern of results was present in the analysis for both hip breadth measures (standing and seated).

\subsection{IMO comparison}

The mean hip breadth seated measurements for the work clothes, uncompressed was less than the criterion of $430 \mathrm{~mm}$. All mean uncompressed, suited values were greater than the $430 \mathrm{~mm}$ criterion. All compressed mean hip breadth seated values were less than the criterion value of $430 \mathrm{~mm}$. The criterion value of $430 \mathrm{~mm}$ represents the 68th percentile score for the seated hip breadth dimension (32\% of the scores were equal to or greater than $430 \mathrm{~mm}$ ) in work clothes uncompressed and 99th \% percentile of the compressed scores.

Comparing the effects of compression on the shoulder breadths it was found that the compression decreased the work clothes breadth by $74 \mathrm{~mm}$ while compression decreased the suited measurements by 134,132 and $127 \mathrm{~mm}$ on suits A, B and C, respectively. None of the mean shoulder breadths measurements for the work clothes or suited condition with or without compression were less than the criterion value of $430 \mathrm{~mm}$. The criterion value of $430 \mathrm{~mm}$ represents less than the $2^{\text {nd }}$ percentile score for this dimension ( $98 \%$ of the scores were greater than $430 \mathrm{~mm}$ ) in work clothes uncompressed and 33 rd percentile for the compressed shoulder breadths. 


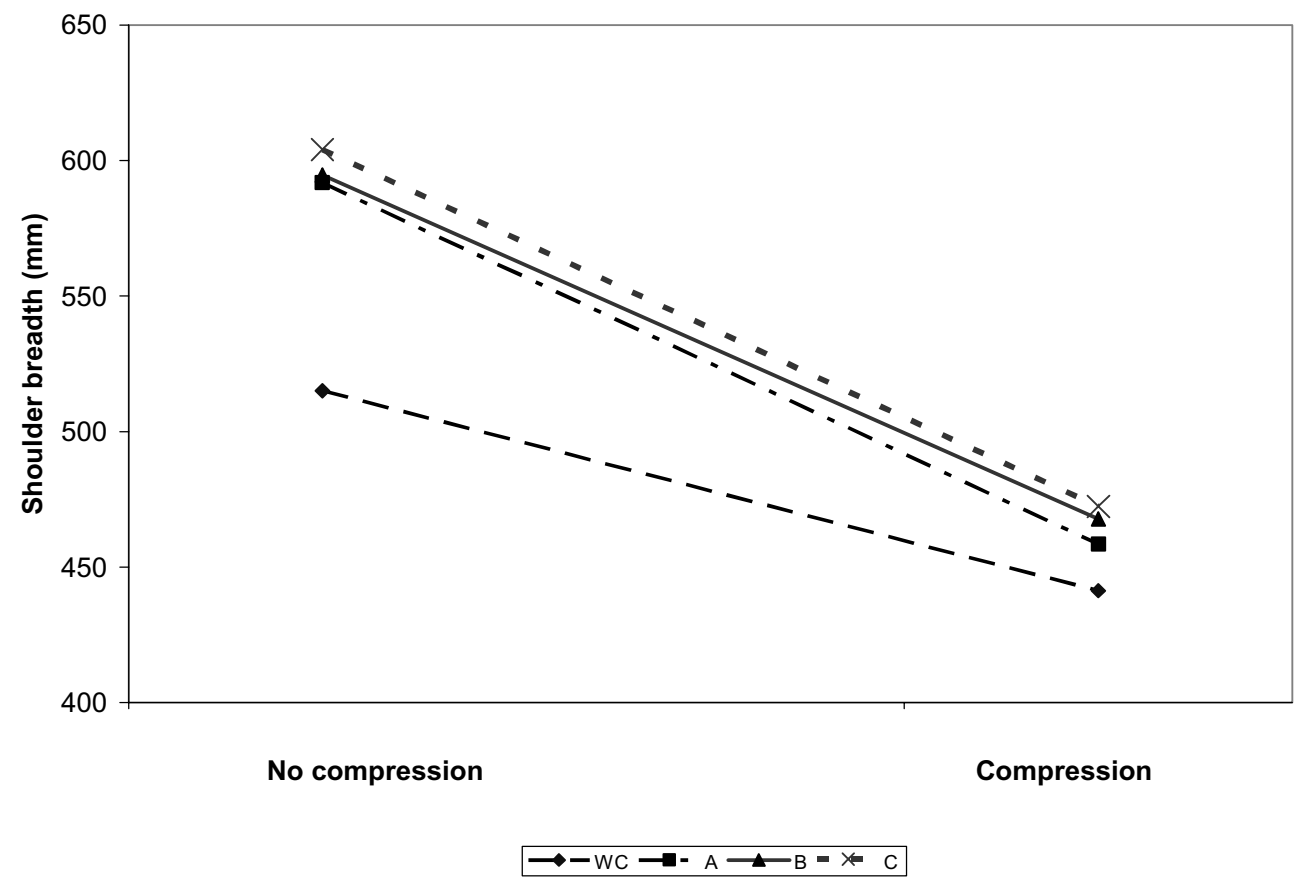

Fig. 5. Shoulder breadth measures (mm) for the different clothing conditions with and without compression.

\subsubsection{Hip breadth seated versus standing}

A comparison was made between the hip breadths of the standing versus seated condition. There is a significant overall mean difference across all suits and conditions that shows the seated hip breadth is greater than the standing breadth by an average of $39 \mathrm{~mm}(t=44.9, p<0.01)$. This is important when comparing the hip breadths to the referenced $430 \mathrm{~mm}$ in the IMO standard. Clearly, seated measures would be most directly related to the seat allocation space, and also represent greater breadths than standing hip breadths.

\subsubsection{Shoulder breadth to hip breadth (seated)}

Lastly a comparison was made between the shoulder breadth and seated hip breadth measures across all conditions. For all cases in work clothes, the shoulder breadth was significantly greater than the seated hip breadth $(t=72.3, p<0.01)$. The overall mean difference between the two measures was 90 $\mathrm{mm}$ while in work clothes. The mean of the difference between the shoulder and hip measures when wearing a suit increased to $105 \mathrm{~mm}$ for Suit A, $123 \mathrm{~mm}$ for Suit B and $111 \mathrm{~mm}$ for Suit C. While the overall mean score increased there were some cases where the hips (uncompressed, Suit A and Suit C) were larger than the shoulders but this was eliminated when compression was applied. The overall mean difference between the shoulders and the hips was significant and equal to $107 \mathrm{~mm}$.

\subsection{Correlational analysis between body mass and shoulder, hip (standing) and hip (seated) measurements}

Pearson Product Moment Correlation values (PPMC) were calculated for the height, mass, BMI and 6 structural dimensions for the data collected in Nova Scotia. The results for the measures taken in work clothes are presented in Table 3. Generally the structural dimensions were more highly correlated to the 
Table 3

Correlation matrix of the body dimensions in work clothes, males and females combined (UC - uncompressed, C-Compressed)

\begin{tabular}{|c|c|c|c|c|c|c|c|c|}
\hline & $\begin{array}{c}\begin{array}{c}\text { Height } \\
(\mathrm{mm})\end{array} \\
\end{array}$ & $\begin{array}{c}\text { Mass } \\
(\mathrm{kg})\end{array}$ & $\begin{array}{c}\mathrm{BMI} \\
\left(\mathrm{kgs} / \mathrm{m}^{2}\right)\end{array}$ & $\begin{array}{l}\text { Shoulder Br. } \\
\text { Standing UC }\end{array}$ & $\begin{array}{l}\text { Shoulder Br. } \\
\text { Standing C }\end{array}$ & $\begin{array}{c}\text { Hip Br. } \\
\text { Standing UC }\end{array}$ & $\begin{array}{c}\text { Hip Br. } \\
\text { Standing C }\end{array}$ & $\begin{array}{c}\text { Hip Br. } \\
\text { Seated UC }\end{array}$ \\
\hline Mass (kg) & 0.49 & - & & & & & & \\
\hline BMI $\left(\mathrm{kgs} / \mathrm{m}^{2}\right)$ & 0.05 & 0.90 & - & & & & & \\
\hline Shoulder Breadth Standing UC & 0.44 & 0.86 & 0.78 & - & & & & \\
\hline Shoulder Breadth Standing C & 0.49 & 0.86 & 0.75 & 0.96 & - & & & \\
\hline Hip Breadth Standing UC & 0.20 & 0.65 & 0.64 & 0.54 & 0.55 & - & & \\
\hline Hip Breadth Standing C & 0.31 & 0.70 & 0.65 & 0.57 & 0.58 & 0.87 & - & \\
\hline Hip Breadth Seated UC & 0.25 & 0.77 & 0.76 & 0.67 & 0.63 & 0.80 & 0.81 & - \\
\hline Hip Breadth Seated C & 0.24 & 0.81 & 0.81 & 0.68 & 0.66 & 0.79 & 0.83 & 0.94 \\
\hline
\end{tabular}

body mass $(0.70$ to 0.86$)$ than the height $(0.20-0.49)$ of the subjects. The correlation between the body mass and the shoulder breadths was moderately high at $r=0.86$. The relationship between the mass and the hip measures were weaker and ranged from 0.65 to 0.81 . The relationship between the shoulder breadths and hip breadths was generally poor ranging from $0.54-0.68$.

\subsection{Simulation model for lifeboat loading capacity}

A mathematical model of the linear space requirements in a lifeboat was developed to compare the measured structural dimensions to the existing IMO code. In this model the criterion value of $430 \mathrm{~mm}$ of linear space for each seafarer was used. Taking the example of the 36 person lifeboat, this would mean that when seated side by side the space requirement would be $(36 \times 430=15480 \mathrm{~mm}) 15.5$ meters. From the sample of 87 Nova Scotian subjects, 36 people were randomly extracted and their linear dimensions used to determine the linear space requirements. Five different random samples were created from the whole data set.

One example of the results of this model is shown graphically in Fig. 6 as a plot of the cumulative length versus subjects. In the figure a horizontal line is drawn at the required space of $15.5 \mathrm{~m}$. As clearly shown in the upper series of lines, using this method for the shoulder breadth dimension only 31 people would fit into the lifeboat sitting comfortably in the uncompressed condition. Also clearly shown in the lower series of lines are the compressed shoulder breadth values and this shows that only 35 people would fit.

\section{Discussion}

The ergonomic research questions described in the objectives of this study will be discussed in five sections to address the problems of change in subjects' structural dimensions when wearing an immersion suit on top of work dress and the impact of the suit on the rating capacities and safe loading of lifeboats.

\subsection{Structural anthropometric dimensions}

The current IMO standard lists a typical body mass and seat width assignment for lifeboats and states:

"The number of persons which a lifeboat to be launched by falls shall be permitted to accommodate shall be equal to the lesser of: 
Fit of Subjects in Lifeboat B

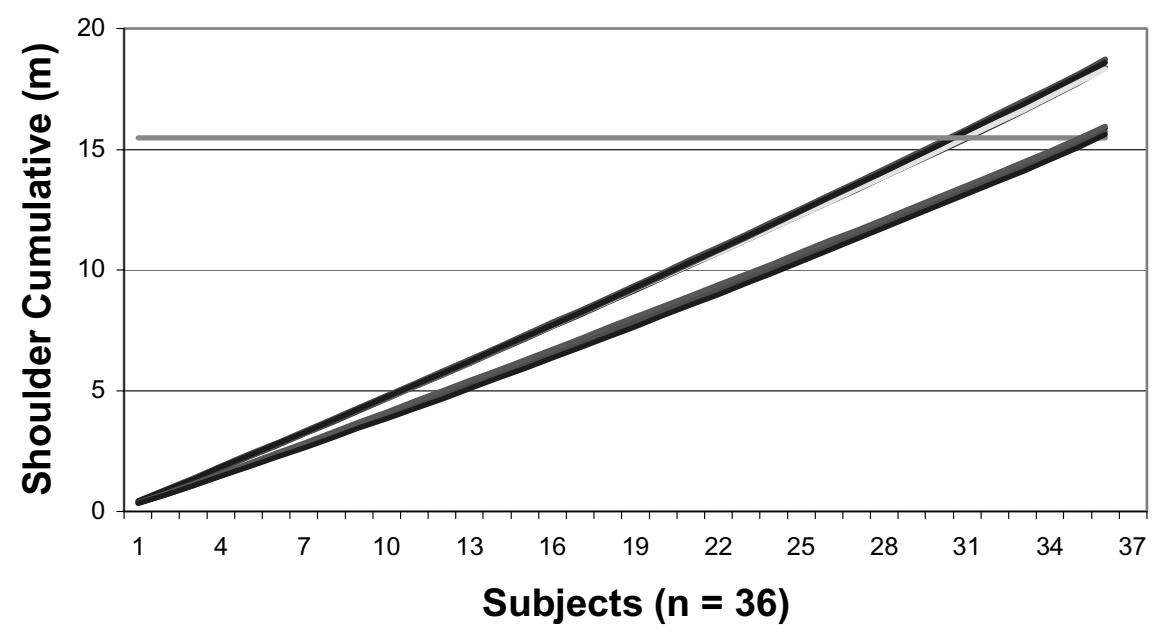

Fig. 6. Comparison of the lifeboat capacity of the model fit to the actual dimensions for the uncompressed and compressed shoulder breadth measures.

1. The number of persons having an average mass of $75 \mathrm{~kg}$, all wearing lifejackets, that can be seated in a normal position without interfering with the means of propulsion or the operation of any of the lifeboat's equipment.

2. The number of spaces that can be provided on the seating arrangements in accordance with Fig. 1. The shapes may be overlapped as shown, provided footrests are fitted and there is sufficient room for legs and the vertical separation between the upper and lower seat is not less than $350 \mathrm{~mm}$.

First and foremost, the two sample populations measured are comparable to each other in terms of height and body mass. They are both considerably heavier than the IMO standard mean value of $75 \mathrm{~kg}$. In fact, $85 \%$ of people had a body mass greater value than $75 \mathrm{~kg}$. The mean body mass for the two populations was 86 and $88 \mathrm{~kg}$. for this study. Two other relevant studies recently reported similar mean body mass values Brooks et al. [1] had mean self-reported measures on 357 offshore oil workers of $89 \mathrm{~kg}$. while Reilly et al. [9] took direct measurements of 42 offshore oil workers and fishermen and found a mean body mass value of $90 \mathrm{~kg}$. Although body mass (weight) is not a good estimator for space allocation, it is an essential measurement for overall weight, stability and impact testing of lifeboats. Therefore, the IMO needs to conduct an international review of basic human anthropometry (weight, height, hips and shoulders) with a view to increasing the current body mass value of $75 \mathrm{~kg}$ to a more realistic description of the workers.

In order to simplify the use and interpretation of standards a "global" measure of the human is often used such as body mass, height or BMI. It has been shown that the relationship between body mass and hip and/or shoulder breadth is quite variable. Therefore using body mass as a predictor of seat space is not a sound policy. As was shown in Table 3, there is only a moderate correlation between body mass and the width of the hips ( 0.65 standing and 0.70 seated) and a slightly improved correlation with shoulder breadth (0.86). The correlation values reported indicate that the body mass only accounts for approximately 42 to $74 \%$ of the variance in hip and shoulder breadths, respectively. These correlations are typical of values reported in the literature on other populations [5].

An important finding is related to the shoulder breadth measurement. In the Nova Scotia population, 85 of the 87 subjects while wearing work clothes had a shoulder breadth measurement uncompressed, greater 
than the $430 \mathrm{~mm}$. All mean shoulder breadth measurements (with and with a suit and/or compression) exceeded the $430 \mathrm{~mm}$. The criterion value of $430 \mathrm{~mm}$ represents less than the $2^{\text {nd }}$ percentile score for this dimension $(98 \%$ of the scores were greater than $430 \mathrm{~mm}$ ) in work clothes uncompressed. With compression but no suit, the value of $430 \mathrm{~mm}$ represents the $33^{\text {rd }}$ percentile value (67\% of the subjects were greater than $430 \mathrm{~mm}$ ). A comparison was made between shoulder breath and hip breadth (seated) measurements. In all cases in work clothing, the shoulder breadth was significantly greater than the hip breadth (seated) by an overall mean value of $90 \mathrm{~mm}$. Therefore the IMO standard for maximum linear width should be measured at the shoulder and not the hip.

The fourth finding is that the existing space allocation of $430 \mathrm{~mm}$ prescribed in the IMO code is not suitable for most marine populations. This was demonstrated directly in the anthropometric dimensions and in the theoretical linear model. Retaining the value of $430 \mathrm{~mm}$ would require each person to rotate his/her pelvis forward on one side and concurrently rotate the corresponding shoulder forward to allow the person on either side to fit in like a jigsaw. This would make for a most uncomfortable fit, which would be an intolerable nightmare for more than half an hour in other than the most calm sea conditions.

The fifth finding was the principal reason for conducting this research in the first place which relates to the effects of wearing an immersion suit on lifeboat capacity ratings. Depending on the type of suit worn by the subjects and the dimension (hip or shoulder), the uncompressed breadths increased by approximately 80 and $45 \mathrm{~mm}$ respectively, when wearing a suit. When the suit is compressed the increase in breadth measurements are significantly reduced. However, the compression would lead extreme discomfort of the passengers in the lifeboat.

The effect of the increases in breadth was shown to reduce the current capacity rating of a lifeboat. Using the accommodation model and the shoulder breadths presented in this study and the criterion value of $430 \mathrm{~mm}$ per seafarer in work dress, the current rating of a 36-person boat should be reduced by $15 \%$ or more. The presence of the abandonment suit increases the size of the seafarer and this would reduce the current capacity rating by closer to $20 \%$ or more. The effect of the suits alone is really only a $5 \%$ or more change. Lifeboats are typically designed and built to hold a limited number of passengers for example the lifeboat shown in Fig. 1 is currently rated to hold 37 passengers. Still other lifeboats are made for lower capacities and some are rated at 50 or more passengers. Therefore the absolute effect of the proposed change in rating will vary based on the current capacity ratings. The 37 passenger lifeboat would be reduced to either 31 or 30 passengers depending the ratings were reduced by 15 or $20 \%$. But, it is important to state that the solution to the problem is to correct the method of space allocation and not the wearing of the suits.

\section{Conclusions}

Based on this investigation, the following conclusions are made:

1. Eighty-five percent of the seafaring population in Atlantic Canada has a body mass greater than $75 \mathrm{~kg}$.

2. The shoulder breadth measurements were always greater than the hip measurements and hip measurements are a poor indicator of space allocation.

3. Shoulder breadth measurement should be used for space allocation. However if IMO does not wish to change the basis for the seat pan measurement, then it should be based on the seated hip breadth measurement and this value needs to be substantially increased from $430 \mathrm{~mm}$. The $95^{\text {th }}$ percentile value (uncompressed) for seated hip breadth in work clothes is $466 \mathrm{~mm}$ and for the suited condition is $511 \mathrm{~mm}$. 


\section{Recommendations}

Based on the conclusions of this study the following recommendations are made:

1. IMO and any other standards writing organization must adjust this value accordingly. However, it would be prudent to compare this value to other international seafaring populations prior to standardizing the value.

2. The current lifeboat rating capacity should be downgraded by approximately $15 \%$ and this value is independent of the issue of wearing an immersion suit.

\section{Acknowledgement}

The authors wish to acknowledge the financial support of Transport Canada, Survival Systems Limited, the Marine Institute and the generous efforts of the subjects to this study.

\section{References}

[1] C.J. Brooks, J. McCabe and J. Lamont, What is the Survival Suit Designed to Do, and Will it Work for Me in the Event of a Ditching or Ship Abandonment? Presented at the NATO-RTO Blowing Hot and Cold: Protecting Against Climatic Extremes Symposium. Dresden, Germany. October 2001.

[2] R. Carrier and P. Meunier, Effects of Protective Equipment on Anthropometric Measurements and Functional Limitations, (DCIEM No: 96-CR-22). North York ON: Department of National Defense, 1996.

[3] H.W. Case, J.F. Annis, T.L. Mayfield, S. Kristensen and D.N. Mountjoy, The effects of clothing on body size and range of joint motion. (Report on the activities and results of phase 1, volume 1: body size). Ohio: US. Anthropology Research Project Inc, 1992.

[4] J.W. Kozey, T. Reilly and C. Brooks, Personal protective equipment affecting functional anthropometric measurement, Occupational Ergonomics 5(2) (2005), 121-129.

[5] K.H.E. Kroemer, Engineering Anthropometry, Ergonomics 32(7) (1989), 767-784.

[6] R.M. Laing, E.J. Holland, C.A. Wilson and B.E. Niven, Development of sizing systems for protective clothing for the male adult, Ergonomics 42(10) (1999), 1249-1257.

[7] L.L. Laubach and M. Alexander, Arm-reach capability of USAF pilots as affected by personal protective equipment, Aviation, Space, and Environmental Medicine 46(4) (1975), 377-386.

[8] A.J.F. MacMillan, Anthropometry and aircrew equipment integration, in: Ernsting's Aviation Medicine, (4th edition), Ch. 15, D.J. Rainford and D.D. Gradwell, eds, Edward Arnold Publishing Ltd., Great Britain, 2006.

[9] T. Reilly, J.W. Kozey and C. Brooks, Structural Anthropometric Measurement of Atlantic Offshore Workers, Occupational Ergonomics 5(2) (2005), 111-120.

[10] N.R. Uppu, F. Aghazadeh and L. Nabatilan, Effect of pressure suit on functional reach, Occupational Ergonomics 6(3) (2006), 129-142.

[11] Webb Associates, Anthropometric Source Book, Volume 1: Anthropometry for Designers, NASA, Ohio, United States, 1978. 